Graham Butt, Jane McNeill, Andy Armstrong

Developing Collaborative Approaches to Enhance the Professional Development of Primary Mathematics

Teachers

Education 3-13: International Journal of Primary, Elementary and Early Years Education (2014), vol. 44 no. 4, pp.

426-441

DOI: $10.1080 / 03004279.2014 .973896$

This version is available: https://radar.brookes.ac.uk/radar/items/4404988f-563f-4fc7-8d87-

fcc4fa04141f/1/

Available on RADAR: 10.11.2016

Copyright ( $)$ and Moral Rights are retained by the author(s) and/ or other copyright owners. A copy can be downloaded for personal non-commercial research or study, without prior permission or charge. This item cannot be reproduced or quoted extensively from without first obtaining permission in writing from the copyright holder(s). The content must not be changed in any way or sold commercially in any format or medium without the formal permission of the copyright holders.

This document is the postprint version. Some differences between the published version and this version may remain and you are advised to consult the published version if you wish to cite from it. 


\section{Developing Collaborative Approaches to enhance the professional development of Primary} Mathematics Teachers.

Jane McNeilla, Graham Butt ${ }_{a} \&$ Andy Armstrong

\section{Abstract}

This research project promoted a collaborative model of professional development between lead teachers from three schools, supported by a project co-ordinator and a researcher from a local university. Each lead teacher worked with their headteacher to design, lead and evaluate an innovative, personalised, school-based mathematics continuing professional development (CPD) programme in their school. University staff helped to facilitate project meetings across the schools and monitored impacts within each school. Professional development meetings, involving all teachers and Teaching Assistants (TAs) from the schools $(n=55)$, were designed to encourage a whole-school approach. The project also provided structured opportunities for the lead teacher to work with colleagues in the classroom, for example through lesson observation and/or collaborative teaching.

The outcomes from this project confirmed that collaborative models of CPD, as opposed to transmission, formal training and 'top down' models, were welcomed by teachers and headteachers - some of whom reported early indications of improvements in student performance. Commenting on what constitutes the most effective forms of CPD, there was a reiteration of the importance of combining peer and external support through a collaborative process.

Keywords: continuing professional development, collaborative approaches, primary mathematics, context model.

\section{Introduction}

In the first few years of the $21^{\text {st }}$ century, primary schools had access to nationally-designed courses and local authority $^{1}$ consultants to support them in implementing the National Numeracy Strategy (DfEE 1999). When the contract for the National Strategies ended, in 2011, the subsequent reduction in teacher support at local authority level meant that schools were increasingly required to pick up the mantle of professional development in mathematics teaching and learning. Academization, and the growing number of 'Free Schools' in England, has further accentuated the issues of schools securing appropriate and timely CPD provision - for although such schools are at least partly funded by the state, they now function largely as autonomous

\footnotetext{
1 Until recently, schools in England have operated within a 'national system, locally administered', as outlined in the 1944 Education Act. This system changed in the early years of the twenty-first century as successive governments promoted greater independence for state schools to manage their affairs.
} 
institutions. Proficiency in mental and written calculation lies at the heart of the mathematics curriculum, as recognised by the emphasis on 'arithmetic' in the re-drafted national curriculum (DfE 2013). In order to meet the expectations of this curriculum, primary schools need to draw on evidence of good practice to inform their development of teaching and learning. One way in which this can be achieved is through carefully tailored programmes of professional development activities.

The research project reported here was designed to both develop and evaluate collaborative approaches for the provision of individualised mathematics CPD programmes within a small group of schools in Oxfordshire, with a view to disseminating methods and findings more widely. Our research, which was part funded by the National Centre for the Excellence of Teaching Mathematics (NCETM) in 2013, provides intelligence about the most appropriate professional development models to employ to improve student proficiency in mental and written calculation. Findings from this research are instructive in suggesting how CPD can have greatest impact on teachers and learners - with significant indicators of success relating to the mode, timing, scale, professional involvement of 'trainers', and sustainability of the relationship between 'trainer and trainee' ${ }^{2}$. Here the reputation and trust of the interventionists (one of whom was a teacher trainer in primary mathematics) were highlighted as being very important by practitioners in schools, as was their relationship with the lead teachers and headteachers. Interestingly, only two of the three lead teachers were mathematics specialists, with selection for the role primarily being driven by pedagogical expertise and a wish to be involved in delivering CPD.

The project promoted collaboration between lead teachers from three schools, supported by a project coordinator and a researcher who together facilitated project meetings and monitored impacts. The nature of this collaborative process is outlined below: each lead teacher, with the support of the project team, evaluated pre-project student proficiency in all four mathematical operations (addition, subtraction, multiplication, division) in order to identify one priority area for development for their school. At project meetings the collaborative team drew on relevant guidance, research and good practice to identify key features of effective CPD in mathematics and to develop successful approaches to CPD within their own school context (ACME 2006, NCETM 2009). Based on the work of this group, each lead teacher worked with their headteacher to design, lead and evaluate an innovative, personalised, school-based mathematics CPD programme to run during the course of the project. Each school's CPD programme sought to enhance teachers' practices to improve children's proficiency in their chosen mathematical operation. The project included professional development meetings which involved the collaboration of all teachers and TAs $(n=55)$ across the schools. It also included structured opportunities for the lead teacher to work with colleagues in the classroom, for example through lesson observation or collaborative teaching. Throughout the project, in addition to regular project meetings, a community discussion site on the NCETM website provided a forum for the project team to share outcomes and ideas about good practice.

\footnotetext{
${ }^{2}$ Although we often use the terms 'trainer and trainee', we acknowledge that in some circumstances a more appropriate description might be 'mentor and mentee', or even 'coach and coached'. Each of these terms is used at certain points in this paper, reflecting the nuanced nature of the roles adopted.
} 
The project co-ordinator and researcher digitally recorded semi-structured interviews with the headteacher and lead teacher in each school, as well as with a representative of the teaching staff, to help assess the effectiveness of the CPD. Evaluation of the impact of the CPD programmes within schools did not include collection of post-project data on student proficiency in the chosen mathematical operation, which might have helped to identify student progress (unfortunately time and resources did not permit such data collection and analysis in this 6 month project). However, some teachers reported early indications of improvements in students' performance in mathematics. Case-study reports, which identified actions taken and the impact of the professional development programme, were produced for each school. The project-co-ordinator also produced a report on the overall outcomes of the project. These were disseminated nationally via the NCETM website in order to provide other primary schools in Oxfordshire, and beyond, with examples of innovative approaches to CPD.

\section{Aims and objectives}

The main aim of the project was to provide a model for within and between-school collaboration which could support the development of effective school-based mathematics CPD. Involvement in the project promoted the sharing of expertise, good practice and innovation in mathematics teaching and learning across the schools involved. The project also offered a platform for the lead teachers to develop their subject leadership and coordination role and to work directly with colleagues in a peer support, or mentoring, capacity.

The key objective was that schools should benefit from a tailored CPD programme to enhance the teaching and learning of their chosen mathematical operation. It was believed that this might improve student proficiency in mental and written calculation and secure teachers' subject and pedagogical knowledge. The in-class support provided by the lead teacher was expected to ensure that this development of subject expertise was embedded in future classroom practice.

\section{Continuing Professional Development}

Defining the concept of continuing professional development (CPD) in education is challenging, given the continuum from 'formal training' to 'on-the job learning'. Bubb and Earley (2007) provide a simple definition, describing CPD as creating opportunities for adult learning to enhance the quality of education in classrooms. However, Day's (1999) earlier definition - which highlights the importance of teachers' roles as change agents in the classroom - is arguably more helpful:

'Professional development consists of all natural learning experiences and those conscious and planned activities which are intended to be of direct or indirect benefit to the individual, group or school, which contribute, through these, to the quality of education in the classroom. It is the process by which, alone and with others, teachers review, renew and 
extend their commitment as change agents to the moral purpose of teaching; and by which they acquire and develop critically the knowledge, skills and emotional intelligence essential to good professional thinking, planning and practice with children, young people and colleagues throughout each phase of their teaching lives.' (p.4)

Teachers' perceptions of what constitutes CPD are bounded by their experience of courses, conferences and whole-school INSET days. In the recent past these have often been arranged to meet nationally determined training requirements representing formalized CPD, quite different from professional, or "on the job", learning (Burns 2005, Edmonds and Lee, 2002; Hustler et al, 2003; Robinson and Sebba, 2004). Lieberman and Grolnick (1996), for example, classifies CPD into three distinct types: direct teaching (such as courses and workshops); learning in school (such as peer coaching, critical friendships, mentoring, action research, and task-related planning teams); and out of school learning (such as learning networks, visits to other schools, and schooluniversity partnerships). Kennedy (2005) extends this classification to nine forms of CPD. The first four (training, award bearing, deficit and cascade) constitute transmission models aimed at addressing teachers' shortcomings, which unfortunately give little opportunity for them to take control over their own learning. The next three (standards-based, coaching and mentoring, and community of practice) are essentially transformational, giving greater opportunities for more meaningful professional development. Transformational approaches may involve the integration of several different models of CPD - possibly incorporating action research and seeking the explicit promotion of professional autonomy - with teachers being given the power to determine their own learning pathways. Our project incorporated elements of Lieberman and Grolnick's (1996) 'in school' and 'out of school' learning, as well as Kennedy's (2005) transformational model.

Traditional 'top down' delivery models of CPD, where teachers are simply passed information to implement, are rarely successful. Edmonds and Lee (2002) assert that lecture-style training has proved unpopular with teachers, who tend to prefer active and practical styles of learning. Dadds (1997) describes how top-down delivery reinforces the idea of the teacher as a technician, uncritically implementing externally imposed policies. He rejects the idea of a 'guru culture', with teachers preferring to use their own experience to develop critical and reflective practices. Recent links between CPD, appraisal and performance management in schools have made teachers more wary of the underlying purposes of professional development, where managerial motives may lie just below the surface (Butt and Macnab 2013). An awareness of less traditional forms of CPD is growing, with teachers becoming creative in their own professional development, facilitating a shift from transmission-based modes of training (Muijs et al, 2004). Nevertheless, Ofsted's (2002) initial evaluation of the impact of the National Numeracy Strategy's centralised professional development was generally positive, suggesting that LA consultants 'played a key role in providing a wide range of good-quality training' (p. 22). This report does, however, acknowledge the limitations of such centralised professional development where key messages are not always effectively disseminated to colleagues in school. Subsequently the Advisory Committee on Mathematics Education (ACME, 2006) suggested that the professional development 
opportunities provided by the National Strategies were so strongly focused on national agendas (such as raising attainment in national tests in Year 6) that they did not always meet the development needs of primary teachers.

\section{Peer Support}

While few teachers would want to divorce themselves from receiving 'expert advice', it is clear that successful CPD programmes will often include a variety of instructional methods, including peer support: 'Teachers need opportunities to reflect, take part in professional dialogue, work with pupils, and engage in peer observation, coaching and feedback' (Livneh and Livneh, 1999). Cordingley et al (2003), in a review of collaborative CPD, noted a number of features of successful interventions. These included classroom observation and feedback; consultation with professionals from outside the school in conjunction with internal peer support; encouraging, initiating and structuring a professional dialogue; teachers developing ownership of their CPD focus; an emphasis on peer support rather than a top-down managerial approach; and sustained management support for CPD to allow new practices to become established. We attempted to institute CPD programmes that included elements of each of these forms of intervention in our collaborative model.

The opportunity to observe peers, and to be observed, has long been identified as an integral part of successful CPD (Joyce and Showers, 2002; Bubb and Earley 2007). This facilitates professional discussion and the exchange of practical and relevant ideas, which many teachers report as being crucial to the success of the CPD experience (Armour and Yelling, 2004; Cordingley et al, 2005a; Edmonds and Lee, 2002; Hustler et al, 2003). However, it is important that this takes place within secure and trusting relationships (Fielding et al, 2005), particularly in the current educational climate where most primary teachers' experiences of classroom observations are closely associated with the stressful evaluations of OFSTED inspectors, or the strictures of performance management. Extending peer observation to peer coaching and mentoring is an increasingly popular model of CPD, effective in improving practice for all (Gersten et al, 1995, Cordingley, 2003, Cordingley et al 2005a, b; Jones and Moor, 2005; Joyce and Showers, 2002). Peer coaching has been found to work most successfully when used in conjunction with classroom observation - with the coach either teaching and being watched, or observing (Livneh and Livneh, 1999). Here modelling of teaching techniques and methods is also often appreciated by teachers (Harvey, 1999; Kimmel et al, 1999). Cochran-Smith and Lytle (1999) describe three types of knowledge: "for practice knowledge", or the use of formal theory about practice; "in-practice knowledge", or the use of interaction and communicating in teaching; and "of practice knowledge", or the awareness of knowledge- generation which tends to be beneficial for teachers in directing their own learning. They suggest that those teachers who have strong "in-practice knowledge" tend to make good coaches. We offered advice to help schools identify such staff, described here as lead teachers, if required and requested. A strong subject and pedagogical knowledge is generally agreed as being essential in a successful coach, although the hierarchical nature of a relationship where the coach is more experienced than the coached may hinder the development of a secure and trusting relationship that allows for open discussion (Fielding et al, 2005). We 
note that in our project only two lead teachers were mathematics specialists, with no apparent negative impact on the effectiveness of the resulting professional development. While peer observation is currently evolving into programmes of peer coaching and mentoring, there is little evidence in the literature about further CPD activities or practices being based on the findings of such observation. Tailoring external support and collaborative activities to what is happening in the classroom before any CPD is undertaken does not seem to have been adequately explored as an approach for professional development. It is this link between existing classroom practice and CPD provision which was explored within this research, with data on student progress being used at the start of the project to provide foci for professional development activities.

\section{External Support}

The use of external experts as agents for change, as in this project, can be beneficial. Small schools in particular can widen their knowledge pool by drawing upon external professional expertise. As the concept of collaborative CPD may represent a shift in culture for many teachers, they may need help in determining their own CPD focus and in identifying the different types of support that are available. It is possible that discussions of this type, with people from outside the school, could reduce anxieties about performance management issues. External support, especially in the delivery of CPD, should be pedagogically expert, and flexible enough to fit in with the varying demands of an individual school's life. Sustained contact with any external parties who were involved in initial input enables issues to be addressed as they arise, and can facilitate motivation, feedback, further discussion and progression (Cordingley et al, 2003; Ross et al, 1999). Following release time for initial training, time is also needed to reflect, consolidate and plan for the implementation of new ideas. Successful interventions have used negotiated non-contact time for teachers as part of the CPD process (Brown et al, 2003; Cordingley et al, 2003, 2005a; Edmonds and Lee, 2002; Fielding et al, 2005), and funding for continued support, has been emphasised as a requirement of effective CPD (Kirkwood, 2001). Here external support provided mathematical and pedagogical expertise, enabling lead teachers to further develop confidence in their mathematics subject knowledge having already established their pedagogical credentials.

\section{Conceptual framework}

Bullock et al (2010) offer a conceptual model of the context of CPD provision (see Fig 1), which has been applied here to position the teachers involved in this research into quadrants (managed, controlled, regulated or liberal) .The consequences of such positioning on teachers' professional practice is considered later.

The model focuses on control, both of the content of the CPD and of who decides on its mode. This is considered with respect to whether it is 'external' to the teacher (that is, control exerted by the state, LA, professional organisation, employer, researcher), or 'individual' (that is, within the person's own choice). The original model notes that the 'external' field is diverse and varied in terms of responsibilities and agency. 
The horizontal axis positions the CPD activity as to whether there is strong external control, such as a designated single accredited provider, or individual control where choice is more varied. The vertical axis represents what is learnt - whether this is externally determined, such as a course linked to the national curriculum or national strategies, or whether the individual has greater control over what is studied.

Figure 1: About here.

Quadrants therefore describe the locus of control for both the mode and content of the CPD provision. Other professional groups (such as medics, dentists, lawyers, accountants, etc) have recently experienced a shift in their mapped location from left to right - that is, the control of the mode of their CPD has tended to become more externally driven (for example with the increase in regulation of number of hours of CPD and an audit of that which has been undertaken), whilst the content is still largely determined by the individual (Bullock et al 2007, Butt and Macnab 2013). The trend for teachers is the reverse, with large scale, externally driven CPD events - linked to national strategies or policy shifts - largely being replaced by more school-centred training. Whilst the model makers comment 'on general shifts only, since this simplistic mapping process masks complexity within the professional groups' (p.85), within the context of the teaching profession they merely offer an observation that the tightness of regulation over CPD can vary between .... primary and secondary school teaching roles' (p.85). They suggest that most teachers lie in the controlled quadrant, proposing that 'it could be argued that teachers' CPD is largely beyond the individual's management' (p.85). The research reported here offers teachers a form of professional development within which they might negotiate, develop, and revise their own professional practice, arguably shifting their location towards the liberal quadrant.

\section{Methods and Methodology}

The aim of the project was to provide a model of within and between-school collaboration developing effective school-based mathematics CPD that could be adopted and adapted by other schools. It was expected to promote the sharing of expertise, good practice and innovation in mathematics CPD, and mathematics teaching and learning, across the schools involved. The project would also provide a platform for the three lead teachers to develop their subject leadership and co-ordination role within their school and to work directly with colleagues in a peer support or mentoring capacity. It was expected that each of the schools would benefit from a tailored CPD programme to enhance the teaching and learning of their chosen mathematical operation and secure teachers' subject and pedagogical knowledge around this operation.

The main source of data was gathered from headteachers, lead teachers and a representative of the teaching workforce in each of the three project schools. This data was gathered from semi structured, one to one interviews undertaken within their schools and later transcribed verbatim. Questionnaires were also 
constructed and distributed across the teaching staff (including TAs and HLTAs) in each of the schools $(n=55)-$ these provided a means of quickly and effectively highlighting issues from respondents who were time poor. They also enabled the researchers to focus on the project aims, providing a source of triangulation with the interview data collected within each school. The composition of the questions designed for the semi structured interviews and questionnaires mirrored the aims of the research, although the interviews provided flexibility for further pursuing issues that either respondent or interviewer believed pertinent. In both the questionnaires and semi structured interviews respondents were asked about their overall experiences of the collaborative model of CPD, but were also prompted to discuss the benefits and drawbacks for their students, the features of the CPD programme they felt were most and least successful in promoting professional development, and what they thought the impact of the project would be in the future. These areas of enquiry helped to define the main themes for the analysis of responses.

The data gathered was therefore predominantly qualitative, with the researchers devising a simple coding system to classify and then analyse the data collected. As the number of respondents was modest this was conducted manually, rather than using analytical software such as Nvivo; key themes were simply noted in the margin of transcripts and questionnaires (for example, comments directly relating to perceived benefits to students' learning (say) would be classified as 'B.Lg'). The themes, reproduced and commented on below, were CPD, time and resources, children's learning, research, and the inclusion of TAs. These themes emerged from the data, rather than being imposed by the researchers. Data was analysed systematically, initially through the identification of specific themes and then by drawing together these themes across the various data sources (interviews, questionnaires, documentation, etc) to ensure the effective triangulation of findings. The interpretation of the data was, of course, that of the researchers - with the subsequent analysis of findings being particular to the individuals involved, despite efforts to achieve objectivity.

\section{Results}

The results include comments that have been made by respondents about the impact of CPD arrangements across or between schools, within their own school, in individual classes, and between teachers and their students. Here a simple coding system identifies the respondent as either a headteacher $(H)$, lead teacher $(L)$, or teacher $(T)$, with the accompanying number identifying the school. (Thus, the headteacher $(H)$ in the first of the three schools (1) was classified as ' $\mathrm{H} 1$ ').

\section{CPD}

The importance of applying effective models of CPD, in this case with a strong collaborative element, was reiterated by the majority of respondents:

'My understanding of effective CPD features has really developed ... in the past there hasn't been the impact and this (project) has really helped me to get staff to take ownership and involve themselves in (CPD) decision making' (H1) 
All respondents in their interviews stressed positive aspects of working collaboratively with other schools, with staff keen to see practice within different contexts (sometimes beyond their established partnerships). There were also benefits acknowledged within schools, where a 'practice gulf' existed in the teaching of mathematics between keys stages 1 and 2, with staff unsure of common practices in different phases. Teachers in each of the project schools recognised that they were involved in a whole school project with links to other schools, introducing a wider range of teaching and learning strategies with opportunities provided to discuss and reflect on these.

However, there were some caveats, as expressed by one of the headteachers:

'Honesty between schools is important, but there are limits to collaboration. We are in competition and not all partnerships are total open about what goes on in their schools. We don't want to put all our weaknesses on the table with neighbouring schools ... there are lots of connections between staff, parents/governors. We are often competing for the same children' $(\mathrm{H} 2)$.

While praising the inter school element, with particular reference to seeing how other schools 'worked', there was mention of confidentiality agreements beyond the school. This contrasted with the atmosphere of communication and trust within the school:

'(there was) support and honesty, but also security in knowing there was no vested interest that 'this, that and the other' can be said. We could speak frankly in our own school; this made a difference - it would not have worked at partnership level' (L2)

The benefits of working collaboratively with other teachers were regularly mentioned:

'we had enough time to plan, to get together and talk about the teaching beforehand, and to evaluate it afterwards - it was 'win-win' really!' (T3)

'joint practice development is the new CPD now! It's the way forward, financially and in terms of resources' (H1)

Many recognised a somewhat different approach to the traditional forms of CPD they had previously experienced, one that gave teachers more ownership of their professional development:

'it was very focused; it included the whole school but was individualised to the teacher .. each teacher identified their own problems and helped to identify the solutions' (T1) 
The nature of CPD provision was also seen to have changed, given the steady demise of support from the LA:

'we've no LA support now, we have to be self-supporting .. we have to borrow ideas from each other, and other schools, and share expertise. We all want our children to do well. We are very much on our own these days!' (T1)

'a change in direction in CPD is hard at first, but we've learnt not to revert to the old, 'easier' strategies - persistence can have rewards' (H3)

'sharing data with other schools is important; partnership heads have been very interested.. but a small trial in three schools has been vital before launching it across 15 schools. School development is very difficult on a large scale, but this is a good model to take forward' (H3)

\section{Time and resources}

Almost all respondents mentioned the availability of time as a significant factor in determining the impact and effectiveness of the CPD:

'No drawbacks... but I would approach it in a better way; I did not spend enough planning time from the start, mapping non-contact time: "half a day here, half a day there" (H1)

The effects of being able to allot more time, over an extended period, to a structured programme of CPD was welcomed:

'The CPD was not radically different from what's gone on before, except that more time and resources were given. More time to discover a solution, rather than just implement a solution from the start' (H2)

The designated use of time was also mentioned, with some describing the time allocation as 'short, but manageable' $(\mathrm{H} 1)$, with pockets of time enabling teachers to reflect on and discuss their practice.

The time of year for the CPD, which ran from January to June, was significant:

'we were slightly rushed.... the time of year is important and the last staff meeting in June was deemed not a good time for CPD!' (H1) 
'there was more time to work in class, to open a dialogue with children - it introduced a process

of problem solving, learners' discussion increased and misconceptions were identified better' (L3)

'we were able to take the time to do things thoroughly' (H2)

It was acknowledged that time, and by implication money (as afforded by this modestly funded project), were necessary to make the CPD effective, but that high quality CPD would use time in particular ways for example, for planning and structuring activities, for the incorporation of research ideas, for review and commentary.

\section{Children's learning}

To legitimate the CPD many teachers needed to see improvements in children's learning as a cornerstone of the project. While the research undertaken did not facilitate the collection of empirical evidence of improvements in children's performance in mathematics, for most respondents the observed effects on children's learning were noteworthy:

'Numerous pieces of evidence from the videos of children's understanding changing' (H1)

For some the role of the teacher had changed:

'from teachers leading to teachers facilitating, such that children are more actively engaged in their learning' (L1)

Children were reported as seeing, and using, a wider variety of learning strategies which had led to significant changes in the levelling of pupils on arrival in one school, and the ways in which they were to be taught subsequently (with children now expected to identify how they solve problems). However, in two of the project schools teachers reported witnessing only a relatively small impact on children's learning during the short life of the project, but a much greater impact on shifting pedagogical practices.

One school's use of video to record classroom practice was regularly mentioned as aiding children's learning, particularly when capturing children's own thoughts and voices on how they were solving mathematical problems:

'it's something we'd like to expand on.. it's promoted discussion and we've thought how we can use video more....... We have a culture in school now where children do not see this as identifying weakness; they see it as a strength especially when they see they have closed a gap' (L1) 
The effects of the project on changing modes of teaching and learning were regularly reported:

'it would be very rare now to see a teacher just teaching from the front and the children just sitting there all googly eyed thinking 'when are we going to be able to do this?" (L1)

Some noted how the involvement of children in the project, making them more responsible and reflective about their own learning, had tangible benefits. A number of students had recognised that they were being taught (and were learning) differently, and were keen to feed back. This in turn had encouraged teachers to consider more fully the children's learning experiences:

'where should this child be at this age and stage? Where should this group be?

Where should they go next?' (L2)

\section{The role of research}

The importance of recognising and incorporating different types of research throughout the project was apparent to both headteachers and teachers. Some commented on the value of engaging with research literature, such as professional and academic journal articles, of discussing research methods, or simply being part of a project that had a research element associated with it. When asked how he might approach a similar project in future one headteacher stated:

'do more research, read more widely before you start' (H1).

Others acknowledged a different way of 'thinking and doing' associated with a research-led project:

'The good thing about it is that it's not about saying 'this is the way to do it'- it's about research; so if it doesn't work for your school you can change the bits that don't work... this sort of project is bespoke' (L1)

'subject knowledge is discussed now in the school; we have some quite academic conversations about content now which point to the 'research and practice gap'. Staff enjoy talking about their pedagogical practice - it's about getting teachers to discuss research, teaching and learning in an enthused and informed way. The project devoted time to this which meant there would be high levels of professional engagement' $(\mathrm{H} 2)$ 
'we liked the use of academic literature and research. Teachers have liked reading the research the NCETM website is great for this. We will continue to weave research into our projects and CPD' (H3)

'The research project gave staff the latitude to experiment; it's been powerful for children's learning and has led to big changes in how the children do maths. The focus of CPD has changed the ways in which we teach maths' (H3)

'the support of the university has been essential - you have facilitated meetings throughout, had 'just enough' contact, helped the organisation of the project and encouraged between school coordination' (L3).

\section{TAs}

Most respondents talked about the effect of the project on the whole staff contingent, including teaching assistants (TAs) and higher level teaching assistants (HLTAs) who were seen to have benefitted from greater inclusions in their school's professional development programme:

'the most successful parts of the CPD model were its openness, frankness, and involvement of all teachers and TAs and NQTs' (H2).

'There has been some CPD 'spill over' for TAs; they have asked for this and staff have asked for their TAs to be trained in this way. It's been good for all staff, the whole school, to see what other staff do' (L2)

'Greater collaboration has been good - it's been useful to share ideas, 'other ways in', to share practice - it's a confidence raiser, as we work alone most of the time. We do work with TAs, but they look to you for the answers. This project has also benefitted them' (T3)

In conclusion, when asked whether the collaborative model of CPD was one which they would wish to repeat in the school, the responses were unanimous:

'we'd definitely like to run this sort of model of CPD again; in terms of giving the staff tasks; making it small and specific, involving the children. By asking the staff to generate their own questions... they had more ownership and responsibility, it involves them more' (H1) 
'we'll use exactly the same model again. Having a staff meeting, seeing where everyone is, teachers designing their own assessment sheets, going away and using them, coming back and discussing what features they've found' (L2)

Even elements that some had feared would be off putting were handled effectively:

\footnotetext{
'we develop that trust - staff are so used to being watched, monitored, corrected, evaluated, graded- we want to get children's learning at the front, starting with the school's needs ..........staff (across the partnership) were really keen; which was really refreshing' (H1)
}

'The project has changed how we do things. It will make a long term difference here' (T2)

\section{Discussion and Analysis}

\section{Collaborative CPD}

The importance of teacher ownership of their professional development has previously been recognised as a feature of highly effective schools, as is the provision of creative CPD opportunities (Connolly and James, 1998). Teachers selecting their own CPD focus can have a positive effect on their motivation, enthusiasm and the take-up of new ideas; frustration tends to result from CPD being 'driven' at management level and from the compulsory nature of its implementation (Edmonds and Lee, 2002; Hustler et al, 2003; Jones and Moor, 2005; Smith et al, 2004). Where CPD activities are imposed, collaboration in small groups can increase feelings of ownership giving teachers a sense of control over future actions (Cordingley, 2005a). Collaborative CPD has benefits compared to individual work, with sustained collaboration of around 3 months appearing to lead to greater teacher confidence and shifts in students' learning. This is also associated with an openness to new ideas and changing practice, a greater enthusiasm for future collaborative working, an increased willingness to be observed, and opportunities for support when teachers are faced with problems and issues of concern (Cordingley et al, 2003, 2005a; Ross et al, 1999). The gains reported from sustained collaboration include facilitating emotional support through the stress of change, and sharing of tasks to ensure better use of time. Such gains are likely to be more evident in pairs or small groups, and in schools rather than at off-site events. Active experimentation, as opposed to just reflection and discussion, also yields greater rewards from sustained collaboration (Cordingley et al, 2005a).

\section{The Impact of CPD}

The BERA-RSA inquiry into research and teacher education recognizes that 'CPD that is not grounded in the world of teachers' every day practice stands little chance of being effective' (Furlong 2014). Inquiry Paper 5 (Cordingey 2013), which highlighted the contribution of research to teachers' professional learning, focused on 
the most effective forms of CPD, concluding that the following features had a significant impact on teacher and student learning:

1. Using specialist expertise

2. Peer support

3. Enquiry oriented learning

4. Learning from looking

5. Aspirations for pupils

6. Understanding why things do and don't work

7. Effective leadership

(Furlong 2014).

Interestingly, the project reported here engaged positively with each of these listed features. The impact of CPD is rarely assessed over the long term, with assessments often being based on self-reports by teachers of the CPD experience itself, rather than its outcome on practice or changes in student performance (Edwards and Lee 2002). This issue is also apparent in our project. Evaluation does not tend to differentiate between the various purposes of CPD, or take account of the intended outcomes. An emphasis on the purpose of CPD before any activities take place may enhance the CPD experience, improving both individual and school-level outcomes (Harland and Kinder, 1997; Muijs et al, 2004). There are a few examples of CPD evaluations considering student outcomes, but these are usually in terms of affective and behavioural changes rather than shifts in academic attainment (Powell and Tewell 2003). Robinson and Sebba (2004) suggest that a clear focus on student outcomes when embarking upon a programme of CPD might result in a greater change in teachers' practice. However, there are potential problems when using test scores to measure student outcomes. The timescale of CPD interventions, as in the project reported here, can cause difficulties whereby not only do teachers have to carry out CPD activities, but also need time to embed any changes in practice, and to assess changes in student performance.

\section{Conceptual model}

With reference to Bullock et al's (2010) conceptual model we would position this CPD predominantly in the bottom left quadrant ('liberal'), typified by high levels of individual control over both the content and mode of the CPD. The conceptual model does not necessarily capture the essence of this project: we would argue that the label 'individual' might be replaced by 'internal' - a more obvious variant to its given opposite of 'external'. We also note that successful collaborative CPD tends to position, or re position, the teacher into different quadrants at different stages of the professional development programme. This re conceptualisation would more accurately capture the nature of schools defining their own CPD programmes, rather than these being determined by the need of the individual teacher. However, the external elements of this project do need to be recognised - the funding of NCETM was significant in making the project work, while all schools mentioned the importance of external drivers (a project co-ordinator and a researcher from a nearby university) in providing 
initial structure, direction and research input. Bullock et al's (2010) conceptual model (like all such models) therefore needs to be applied with caution, recognising that external and internal drivers to CPD can be complex and can have either positive or malign effects. This project reverses the trend of CPD moving towards the 'controlled' quadrant of the model (stronger external control of both content and mode of delivery), acknowledging previous research which indicated that local conditions can alter or even reverse the trend towards greater choice for the individual teacher (Butt and Macnab 2013). Collaborative CPD appears to 'mix up' the teacher's positioning within the quadrants - not least because the mode and content of CPD is influenced by across/between school professional development activities, mediated by an external source (the university), and may have significant peer-peer elements linked to classroom-based activity within each school. In this latter context it was apparent that agendas were regularly being set by the teachers themselves. The continuum between 'external' and 'individual' therefore get blurred at different stages of the CPD. For example, it might be argued that at the start of the project teachers would have predominantly sat within the managed quadrant, as they experienced the strong external influence of a research project 'run' by a university and funded by NCETM. At this stage it would appear that teachers would have no direct control of the form and content of the CPD in their schools. As time progressed the locus of control shifted, with an increasingly collaborative model taking centre stage. The importance of balancing the input of external drivers with the internal needs of the school and individual teachers is recognised by this shift in location.

\section{Conclusions}

Some clear messages emerged from this research. While for many schools the project built upon already wellestablished foundations for deploying effective CPD, there were also revelations and emergent action points with respect to future professional development practice ${ }^{3}$. Across the teaching workforce time-honoured comments about successful CPD were again voiced (the need for strong leadership and support from senior managers, a recognised area for development being addressed, appropriate allocation of time and resources, adoption of a whole school approach), but many of these comments were nuanced with reference to the newly perceived benefits of collaborative working (with universities, subject experts, researchers, peers, and students). These respondents regularly mentioned qualities of co-operation, openness, frankness, the importance of involving all teachers and TAs, collectiveness, shared problem solving, and the benefits of giving teachers tasks to undertake and then getting them to report back their findings to staff meetings.

There was unanimous praise for the use of video-recorded evidence of how teachers worked with children, how children worked together, and how learners explained their own understanding of mathematical concepts. These practices built on existing NCETM website materials, but the recording of the children's own operations brought a new and powerful dimension to CPD across the schools. The videos were regularly identified as highlighting children's misconceptions and clarifying the language they used in concept

\footnotetext{
${ }^{3}$ We note that in November 2013, after the culmination of the project, ACME published new guidance on the features of effective CPD in mathematics, which includes a section specifically focused on the benefits of collaborative approaches.
} 
development. The need for a clear focus for the programme of CPD - driven by the children's learning needs was therefore perhaps an obvious, but significant, finding; particularly with respect to teachers avoiding preconceptions of what their children knew, understood and could do.

The factors that account for the successful implementation of a collaborative model of CPD were captured by the following comments:

'The key factors in making this CPD work were the strength of leadership, and enthusiasm, of our headteacher. There also needed to be respect and a feeling that there is a 'point' to the CPD - a 'start, middle and end' to the project. It was well structured and run from the children's needs' (T1)

'its success was down to: clear project aims, high levels of staff involvement, university involvement, choosing the right theme to invigorate staff, getting the engagement of all the staff, and picking a genuine problem that staff knew had to be solved' $(\mathrm{H} 2)$

With reference to establishing successful modes of professional development, Day (1993) has previously commented that teachers need to work in cultures that help them to collaborate, whilst monitoring and regulating their own practices. This involves the provision of appropriate CPD, with the support and encouragement of senior managers:

'collaborative cultures, collegiality, contract-making, entitlements and critical friendships (are) built through openness and trust .... Reinforcing a sense of autonomy with responsibility by affirming confidence in teachers' professionalism' (p.89) 


\section{References}

ACME (2006) Ensuring effective Continuing Professional Development for teachers of mathematics in primary schools. Accessible at: http://www.acme-

uk.org/media/1451/acme ensuring\%20effective\%20continuing\%20professional\%20development\%20for\%20te achers\%20of\%20maths\%20in\%20primary\%20schools.pdf

ACME (2013) Empowering Teachers: Success for Learners Accessible at: http://www.acmeuk.org/media/14054/acmepdreport2013.pdf

Armour, K. M. and Yelling, M. (2004) Professional 'development' and professional 'learning': Bridging the gap for experienced physical education teachers. European Educational Review, 10, 71-93.

Brown, M., Askew, M., Millett, A. and Rhodes, V. (2003) 'The key role of educational research in the development and evaluation of the National Numeracy Strategy'. British Educational Research Journal, 29 (5), 655-672.

Bubb, S and Earley, P (2007) Leading and Managing Continuing Professional Development. $2^{\text {nd }}$ Edition. London: Paul Chapman Publishing

Bullock, A, B, Firmstone, V,R, Frame, J and Bedward, J (2007) Enhancing the benefit of Continuing Professional Development : a randomized controlled study of personal development plans for dentists. Learning in Health and Social Care 6 (1) pp.14-26.

Bullock, A, D, Firmstone, V,R, Frame, J and Thomas, H (2010) Using dentistry as a case study to examine continuing education and its impact on practice. Oxford Review of Education, 36 (1) pp.79-95.

Burns, C (2005) Tensions between National, School and Teacher Development Needs: a survey of teachers' views about continuing professional development within a group of rural primary schools. Journal of In-Service Education vol. 31, no. 2 (2005) p353- 372.

Butt,G and Macnab, N (2013) Making connections between the appraisal, performance management and professional development of dentists and teachers. Professional Development in Education. Vol 39 (5) pp.841861. 
Cochran-Smith, M. and Lytle, S. L. (1999) Relationships of knowledge and practice: Teacher learning in communities. Review of Research in Education, 24, 249-305.

Cordingley, P (2013) The contribution of research to teachers' professional learning and development. Research and Teacher Education: BERA-RSA Inquiry Paper 5. Accessible at:http://www.bera.ac.uk/wpcontent/uploads/2013/12/BERA-Paper-5-Continuing-professional-development-and-learning.pdf

Cordingley, P., Bell, M., Evans, D. and Firth, A. (2005a) The impact of collaborative CPD on classroom teaching and learning. Review: What do teacher impact data tell us about collaborative CPD? In Research Evidence in Education Library. London: EPPI-Centre, Social Science Research Unit, Institute of Education, University of London.

Cordingley, P., Bell, M., Rundell, B. and Evans, D. (2003) The impact of collaborative CPD on classroom teaching and learning. In Research Evidence in Education Library. Version 1.1. London: EPPI-Centre, Social Science Research Unit, Institute of Education.

Cordingley, P., Bell, M., Thomason, S. and Firth, A. (2005b) The impact of collaborative continuing professional development (CPD) on classroom teaching and learning. Review: How do collaborative and sustained CPD and sustained but not collaborative CPD affect teaching and learning? In Research Evidence in Education Library. London: EPPI-Centre, Social Science Research Unit, Institute of Education, University of London.

Dadds, M. (1997) Continuing professional development: Nurturing the expert within. British Journal of InService Education, 23 (1), 31 - 38

Day, C (1993) Reflection: a necessary but not sufficient condition for professional development. British Educational Research Journal, 19, (1), p.83-93.

Day, C., (1997) In-service teacher education in Europe: conditions and themes for development in the 21st Century. British Journal of In-Service Education. vol 23 p39-54

Day, C. (1999) Developing Teachers: The Challenges of Lifelong Learning. London: Falmer Press.

DfE (Department for Education) (2013) National Curriculum in England: mathematics programmes of study. Accessible from https://www.gov.uk/government/publications/national-curriculum-in-england-mathematicsprogrammes-of-study.

DfEE (Department for Education and Employment) (1999) National Numeracy Strategy: Framework for teaching mathematics. London DfEE 
Edmonds, S. and Lee, B. (2002) Teacher feelings about continuing professional development. Education Journal, 61, 28-29.

Fielding, M., Bragg, S., Craig, D., Cunningham, I., Eraut, M., Gillinson, S., Horne, M., Robinson, C., and Thorp, J. (2005) Factors Influencing the Transfer of Good Practice. Research report for the Department for Education and Skills, RR615.

Furlong, J (2014) Why Research Matters: lessons from the BERA-RSA inquiry into research and teacher education. Keynote Address, Research Conference, School of Education, Oxford Brookes University, 27 June 2014.

Gersten, R., Morvant, M. and Brengelman, S. (1995) Close to the classroom is close to the bone: Coaching as a means to translate research into classroom practice. Exceptional Children, 62, 52-66.

Harland, J. and Kinder, K. (1997) Teachers' continuing professional development: Framing a model of outcomes. British Journal of In-Service Education, 23 (1), 71 - 84

Harvey, S. (1999) The impact of coaching in South African primary science INSET. International Journal of Educational Development, 19, 191-205.

Hustler, D., McNamara, O., Jarvis, J., Londra, M., Campbell, A. and Howson, J. (2003) Teachers' Perspectives of Continuing Professional Development: DfES Research Report No. 429, London: DfES.

Jones, M. and Moor, H. (2005) The impacts of professional development for teachers early in their careers. Paper presented at BERA annual conference, University of Glamorgan, 14 - 17 September 2005.

Joyce, B. and Showers, B. (2002) Student Achievement Through Staff Development. (3rd Edition) London: Longman.

Kennedy, A. (2005) Models of continuing professional development: A framework for analysis. Journal of InService Education, 31 (2), 235-250.

Kimmel, H., Deek, F. P., Farrell, M. L. and O'Shea, M. (1999) Meeting the needs of diverse student populations: Comprehensive professional development in science, math and technology. School Science and Mathematics, 99, 241-249. 
Kirkwood, M. (2001) The contribution of curriculum development to teachers' professional development: A Scottish case study. Journal of Curriculum and Supervision, 17, 5-28.

Lieberman,A and Grolnick, M (1996) Networks and Reform in American Education. Teachers' College Record, 98 (1), 7-45.

Livneh, C. and Livneh, H. (1999) Continuing professional development among educators: Predictors of participation in learning activities. Adult Education Quarterly, 49, 91-106.

Muijs, D., Day, C., Harris, A. and Lindsay, G. (2004) Evaluating continuing professional development: An overview. In C. Day and J. Sachs (eds.) International Handbook on the Continuing Professional Development of Teachers. Ballmoor, Bucks: Open University Press.

NCETM (2009) Researching Effective CPD in Mathematics Education: Final Report. Accessible at: https://www.ncetm.org.uk/public/files/387088/NCETM+RECME+Final+Report.pdf

OfSTED (2002)The National Numeracy Strategy: the first three years 1999-200. London: OfSTED.

Powell, E., and Terrell, I., (2003) Teachers' perceptions of the impact of CPD: an institutional case study. Journal of In-Service Education. vol. 29. no. 3 (2003) p389-404

Robinson, C. and Sebba, J. (2004) A Review of Research and Evaluation to Inform the Development of the New Postgraduate Professional Development Programme. TTA / University of Sussex.

Ross, J, Rolheiser, C., and Hogaboam-Gray, A. (1999) Effects of collaborative action research on the knowledge of five Canadian teacher-researchers. Elementary School Journal, 99, 255- 275.

Smith, F., Hardman, F., Wall, K. and Mroz, M. (2004) Interactive whole class teaching in the National Literacy and Numeracy Strategies. British Educational Research Journal, 30 (3), 395-411. 
